\title{
SOBERANIA SOB A PERSPECTIVA JURÍDICO-FILOSÓFICA RUSSA
}

\author{
SOVEREIGNTY IN THE LIGHT OF RUSSIAN LEGAL PHILOSOPHY
}

Mikhail Antonov*

RESUMO: no presente artigo analisaremos uma das tendências da filosofia jurídica russa que exerce uma influência considerável nos atuais processos políticos deste país. Essa tendência manifesta-se no chamado centralismo estatal: uma ideologia segundo a qual o Estado é onipotente e pode interferir em qualquer assunto, sem nenhuma limitação interna ou externa. Essa "ideologia do Leviatã" foi por muitas vezes articulada na filosofia jurídica; para começar, com Platão e Aristóteles, e, na Rússia, encontrou um solo fértil, pois seus territórios devastados, sua população heterogênea e seu ambiente pouco amigável (tanto política quanto naturalmente) deixaram claro para muitos que, sem autoridades centrais fortes, não haverá futuro para esse país tão grande. Em resumo, ou a Rússia ruirá como a Inglaterra, a França e outros impérios, ou precisará se modernizar e se reestruturar de acordo com os modelos de outros grandes países ocidentais (como os EUA). Este artigo foi desenvolvido com base em duas palestras que o presente autor apresentou em 2013 e em 2014 na Faculdade de Direito da Universidade Federal do Paraná graças ao convite e suporte desta Faculdade e aos esforços incansáveis do Professor Cesar Antonio Serbena. Nós sinceramente esperamos que este artigo seja uma importante adição às palestras e que seja de alguma ajuda aos nossos colegas brasileiros que buscam compreender a situação política atual da Rússia, assim como implicações e perspectivas sob a luz dos debates filosóficos que permeiam estes discursos.

PALAVRAS-CHAVE: Rússia. Soberania. Filosofia do Direito.

ABSTRACT: In the present paper we will analyze one of the trends of Russian legal philosophy which exerts a considerable influence on the political processes on-going in this country. This trend is revealed in so called state-centralism: an ideology according to which the State is omnipotent and can interfere with any matters without any limitation from inside or outside. This "ideology of Leviathan" has been many times articulated in legal philosophy, to begin with Plato or Aristotle. In Russia this ideology has found a fertile soil, as its waste spaces, heterogeneous population and unfriendly environment (both in political and natural senses) made it clear for many that without powerful central authorities there will be no further for such a big country. To wit, it will either fall apart as the French, British and other empires, or will need to get modernized and restructured according to the models of other big Western counties (like the US). This paper is developed on the base of two lectures that the present author gave in 2013 and 2014 at Law School of the Federal University of Parana grace to kind invitation and support of this School and to relentless efforts of

\footnotetext{
* Professor de Direito e Diretor do Departamento de Teoria e História do Direito da Escola Superior de Economia de Moscou (Rússia). Doutor em Direito pela Saint-Petersburg State University (2006). As atividades de investigação se concentram na história da filosofia legal russa, na filosofia contemporânea do direito, na formação da jurisprudência sociológica e nos problemas de soberania no direito público.E-mail: mich_antonov@voila.fr

Tradução para o português e revisão técnica por Cesar Antonio Serbena (professor adjunto das disciplinas de Filosofia do Direito e Teoria do Direito nos cursos de Graduação, Mestrado e Doutorado em Direito da UFPR. E-mail: cserbena@uol.com.br) e por Cesar Bolzani (Mestrando em Direito das Relações Sociais pela Universidade Federal do Paraná. E-mail: cesarbolzani@gmail.com).
} 
Professor Cesar Serbena. We do hope that this paper will be an important adjunct to our lectures and will be helpful to those of our Brazilian colleagues who seek to understand the actual political situation in Russia, its implications and perspectives in the light of philosophical debates that underpin these discourses.

KEYWORDS: Russia. Sovereignty. Legal Philosophy.

\section{INTRODUÇÃO}

Várias tentativas foram empreendidas para modernizar a Rússia - uma das mais conhecidas foi o projeto de reformas lançadas no século XVIII pelo czar Pedro, O Grande. A Revolução Bolchevique, em 1917, e a perestroika, nos anos 90, também podem ser consideradas como tais tentativas. Porém, nenhuma delas trouxe qualquer sucesso considerável para a ocidentalização do País, e tampouco o modelo de centralização forte jamais foi reformado. Essa situação explica por que tantos russos atualmente defendem valores conservadores, entre os quais os do "Estado forte”, da “moralidade tradicional” e da “justiça social”. Mais ainda, esses valores coletivos sempre estiveram sob atenção dos filósofos políticos russos e foram utilizados para suprimir os valores individuais (liberdade, autonomia e autogoverno) nas discussões dos filósofos do direito.

Um dos conceitos utilizados atualmente pelos políticos russos (e pelos ideólogos que legitimam suas políticas) é o da "soberania”. Em épocas passadas do centralismo estatal russo o conceito foi justificado com referência à missão especial da Rússia enquanto protetora da cristandade genuína (i.e., Ortodoxia na Rússia Imperial) ou enquanto libertadora da humanidade, contra a injustiça e a exploração (a ideologia comunista). Essas referências encontram-se agora desatualizadas e a nova "missão histórica” do Estado russo, de acordo com a ideologia oficial, é a proteção da lei e da ordem internacionais e da moralidade tradicional, atacadas pelo Ocidente. O conceito-chave para esse efeito é o entendimento tradicional da soberania enquanto absoluta independência estatal em relação à pressão interna e externa. A seguir (capítulo 2) demonstraremos a base de aplicação desse conceito na vida política e jurídica da Rússia e, em particular, nos discursos da elite política e na argumentação da Corte Constitucional russa. Antes de começar esta análise, delinearemos as principais tendências do desenvolvimento da filosofia jurídica russa no século XX (capítulo 1) para demonstrar a estrutura intelectual em que esses discursos foram assumidos. 


\section{CAPÍTULO 1}

Às vezes se fala sobre uma “misteriosa alma russa”, uma civilização que se opõe tanto às culturas ocidentais quanto orientais. Muitos pressupostos filosóficos foram formulados sobre essa questão, que continua a ser decisiva para os procedimentos legislativos e políticos na Rússia. Pode ser implícito, mas, ainda assim, uma ou outra perspectiva está sempre presente nessas reformas, como naquelas da perestroika, que carregavam as ideias de ocidentalização ou, mais tarde, a política isolacionista de Putin, baseada na concepção eslavófila de singularidade da civilização russa, carregando ideológica, política e economicamente consigo a filosofia da Eurasian Economic Union (e.g., o grande projeto político dos últimos anos foi a criação da Eurasian Union na base, exceto pelos países bálticos, da antiga União das Repúblicas Socialistas Soviéticas - URSS). Isto levou aos últimos eventos na Ucrânia - apenas para demonstrar um exemplo da influência de ideias filosóficas sobre o Estado, o direito e nossa vida em geral. Da última vez, minha palestra foi dedicada à polêmica filosófica entre os ocidentalizadores, que propõem a globalização, e os neoeslavófilos, que insistem que a Rússia deveria seguir seu próprio caminho, protegendo sua cultura e o Estado da influência decadente do Ocidente. Nesta base filosófica é que emergiu e caminha até hoje a discussão sobre a soberania russa e seus limites. No que segue, farei um esboço do desenvolvimento da filosofia jurídica na Rússia nas três primeiras décadas do século XX, que servem como base para os debates contemporâneos. Concentrar-me-ei em apresentar uma breve descrição das principais linhas filosóficas do início do século $\mathrm{XX}$, que foram centrais para a consequente evolução de ideias neste século. Depois de um período de relativa estagnação filosófica do pensamento jurídico (causada pela forte censura ideológica que perdurou dos anos 30 até a perestroika - pularei esta parte para ser breve) essas ideias reemergiram nos debates políticos. Até mesmo o grupo político no parlamento russo representa, de certa maneira, a diversidade de ideias jurídicas e políticas (quatro partidos maiores: Rússia Unida - o partido de Putin -, que defende um Estado forte e um direito positivo, contra os filósofos do direito natural; Partido Comunista, que, evidentemente, apega-se à filosofia jurídica marxista; Apenas Rússia, que defende o direito natural; Partido Democrático-Liberal - com o ultraconservador Zhirinovsky -, que opõe a Rússia ao Ocidente e defende um direito consuetudinário). De tempos em tempos, políticos, juízes e advogados articulam suas posições de acordo com uma visão das doutrinas filosóficas russas (e não apenas nos casos de soberania), de maneira que o passado filosófico ainda se mantém presente.

A filosofia do direito russa se desenvolveu nas principais correntes do direito natural. Mas, no fim do século XIX, o poderoso impacto da secularização dividiu a cultura acadêmica russa e transformou-a em uma luta entre liberais, radicais e tradicionalistas em todos os ramos das ciências 
sociais, incluindo a Ciência do Direito. Os desgastados rótulos “positivismo” e “idealismo” podem ser aplicados apenas sob a condição de que essa distinção não denota necessariamente qualquer afiliação política. É verdade, por outro lado, que o governo Imperial da Rússia promoveu o idealismo, combinado com o tradicionalismo e o misticismo, como bases de sua ideologia oficial, e tendeu a banir a filosofia positivista que desafiava a fórmula filosófica sagrada e tradicional de Ortodoxia, Autocracia, Nacionalidade (Pravoslavie, Samoderhavie, Narodnost). Porém, o efeito pareceu ir na direção oposta: a censura czarista, a vigilância e a repressão contribuíram para a crescente popularidade da ideologia positivista na sociedade russa. A escolha que eu faço entre as várias doutrinas é pragmática - para esclarecer: de acordo com a influência exercida pelas concepções nos debates contemporâneos.

O marxismo e o anarquismo foram as principais inspirações da Revolução de Outubro na Rússia, em 1917. Na segunda metade do século XIX, a ideologia anarquista exerceu uma influência notável na vida política russa. A atividade de Mikhail Bakunin e seus seguidores provocou o tradicional ceticismo russo em relação ao Estado e ao direito. O abismo entre a experiência ideológica religiosa do poder e as leis promulgadas por ele, de um lado, e o conteúdo dessas leis e sua implementação prática, de outro, representaram um solo fértil no qual o anarquismo conseguiu promover vários movimentos populares. Estes movimentos, e a ideia de repudiar a esfera jurídica como incompatível com as crenças morais e religiosas, encontraram um suporte poderoso no trabalho literário do novelista russo Leo Tolstoy (1828-1910). Tolstoy teve um grande impacto, inclusive, para além da literatura russa: suas denúncias e críticas morais contra o Estado e o direito tornaram-se um dos principais fatores no desenvolvimento da filosofia jurídica russa na virada do século. A maioria dos trabalhos que ele escreveu à época expressam uma rejeição resoluta de qualquer poder que não o poder de Deus. Ainda que em seus trabalhos mais ilustres Tolstoy tenha atacado o sistema jurídico russo, seu alvo não era apenas esse ou aquele regime ou conjunto de leis, mas a própria ideia de coerção encarnada no Estado e no direito. Muitos tornaram-se seguidores de sua doutrina de não-coerção e reuniram-se em comunidades reivindicando liberdade em relação a qualquer regulação jurídica.

Os primeiros passos do marxismo na Rússia não mostraram promessas de algum sucesso extraordinário, e nem mesmo foi possível perceber a influência que esta ideologia iria exercer na história russa. O Partido Marxista Russo nasceu em meados de 1890 e foi primeiramente encabeçado por George Plekhanov (1857-1917). Convencido da inevitabilidade da revolução social, Plekhanov advogou por um progressivo trabalho reformativo, feito passo a passo por meio da legislação, um processo destinado a levar ao desenvolvimento industrial e político e ao consequente 
crescimento da classe trabalhadora: isto, por sua vez, estava fadado a mudar o sistema de produção, desembocando numa subsequente revolução social. No início do século XX aconteceu uma cisão entre os mencheviques, liderados por Plekhanov, e os bolcheviques - estes últimos (Lenin, Trotsky) sendo persuadidos da futilidade de qualquer reforma jurídica liberal burguesa, que não alcançaria nada além de desviar o povo trabalhador da atividade revolucionária.

Quando a Guerra Civil Russa chegou ao fim, vários filósofos mais jovens afirmaram que a Revolução ocorreu por causa do cosmopolitismo favorecido pelo regime anterior, que tentou introduzir valores jurídicos ocidentais na Rússia, sem perguntar se esses valores eram compatíveis com o ethos do povo russo. Estes autores consideraram o bolchevismo como uma reação natural contra tal ocidentalização, acreditando que seria suplantado por um Estado forte consolidado por meio de um direito dos costumes. Essa lógica foi seguida pelo eurasianismo, que insistiu que a Rússia não pertencia nem à Europa e nem à Ásia, e dá continuidade às práticas jurídicas dos bizantinos e dos tártaros, enquanto cria sua própria realidade jurídica baseada nos padrões culturais herdados de sua história e geografia.

O idealismo no direito não leva necessariamente para a afirmação de valores democráticos, e esse também foi o caso na filosofia jurídica russa. Assim, perseguindo as premissas idealistas do hegelianismo, Ivan Iljin (1883-1954) desenvolveu uma concepção jurídica autocrática, em muitos aspectos similar à concepção de Carl Schmitt. A abordagem do direito de Iljin teve seu início no objetivo de refutar a teoria anarquista e niilista de Leo Tolstoy, protegendo assim o direito, contra uma intrusão niilista que poderia solapar o valor da regulação jurídica. Iljin afirma que o direito escora-se em valores espirituais comunitários que unem os indivíduos em comunhões jurídicas. Essa concepção foi desenvolvida no livro mais memorável de Iljin, On the Essentials of Legal Consciousness [Sobre os Fundamentos da Consciência Legal], investigando a natureza da consciência jurídica. Na opinião de Iljin, essa consciência coincide com a vontade de obedecer aos comandos das autoridades, desde que esses comandos sejam legitimados. A legitimação pode ser alcançada de duas maneiras: por meio da igualdade ou da hierarquia, uma distinção que Iljin diz ser essencial ao distinguir entre as duas formas principais de governo - a república ou a monarquia-, temas de sua obra On Monarchy and Republic [Sobre a Monarquia e a República]. Por um lado, existe uma "consciência jurídica republicana", que favorece a independência individual e é característica da civilização ocidental; Por outro, temos uma “consciência jurídica monárquica”, que, na visão de Iljin, defende a harmonia coletiva e combina perfeitamente com os arquétipos culturais russos. Enaltecendo esta última forma, Iljin afirmou que devem ser impostas limitações aos direitos 
liberais até que uma pessoa integre completamente seus valores culturais e cresça em uma entidade espiritual capaz de fazer um sábio uso de sua liberdade.

Na filosofia do direito russa, ao lado da corrente "idealista" - e competindo com ela também existiu uma corrente "positivista”, na qual se podem distinguir várias abordagens: normativa, sociológica, psicológica, entre outras. Um representante típico da abordagem normativa na Rússia, assim como seu representante mais ilustre, foi Gabriel Shershenevitch (1863-1912), que seguia as ideias de John Austin e de outros defensores da teoria do comando. Ele insistiu que a característica básica das normas jurídicas está na coerção do Estado e nas sanções que os representantes do Estado podem impor, de maneira que o Estado, lógica e historicamente, precede o direito. O direito é a reação do povo à incerteza, pois ele (o povo) se protege da incerteza emitindo normas e diretivas obrigatórias; a partir disso, Shershenevitch infere que o critério último do direito está na sua previsibilidade. Ainda que, em comparação com os positivistas ocidentais, Shershenevitch não tenha trazido nada de original, ele de qualquer forma marcou uma fase importante no liberalismo russo.

A abordagem sociológica foi particularmente fértil na Rússia Imperial. O pensamento sociológico foi visto pelas autoridades como pensamento revolucionário e, por essa razão, o ensino de sociologia foi oficialmente banido até a queda do regime político em 1917. Portanto, foi apenas em Paris que o famoso sociólogo russo-ucraniano Maxim Kovalevsky (1851-1916) pode abrir seu Instituto Russo de Sociologia, já que era impossível abrir um instituto sociológico na Rússia. Internacionalmente reconhecido como o principal antropologista jurídico da virada do século, Kovalevsky seguiu a filosofia do solidarismo de Émile Durkheim e demonstrou habilmente como a regulação jurídica em sociedades humanas lentamente desenvolve padrões, e como esses padrões tornam-se relativamente uniformes. Esse processo de “expansão jurídica” não chega ao fim com o aparecimento do Estado - grupos sociais não deixam de formar padrões, continuando a desenvolvêlos mesmo em face das autoridades.

O bolchevismo estava cometido em suprimir tais ferramentas de exploração de classe, como o direito e o Estado, mas, na verdade, depois do golpe de Estado em 1917, buscou reforçar os poderes de Estado e sua maquinaria administrativa. Foi para resolver essa contradição que, em 1918, o líder bolchevique, Vladmir Lenin (1870-1922), escreveu seu famoso Estado e Revolução, que forneceu a base para o desenvolvimento de uma filosofia jurídica marxista-leninista nos muitos anos por vir. Lenin sustentou que para superar a exploração de classe seria necessário, em primeiro lugar, suprimir as classes competidoras pelo estabelecimento de um Estado forte e poderoso, controlado por autoridades ideológicas. Para Lenin, não havia espaço para o direito no Estado 
Soviético, já que o direito era reconhecido como parte da superestrutura típica da propriedade privada. Assim que os meios de produção fossem nacionalizados, o direito restaria aplicável apenas na esfera limitada das relações privadas e logo desapareceria.

Essa linha de pensamento rigorosa foi desenvolvida por Evgeny Pashukanis (1891-1937), famoso por seu trabalho Exchange Conception of Law. Esta concepção foi primeiramente delineada em 1924, no seu trabalho intitulado The General Theory of Law and Marxism, no qual Pashukanis afirmou que o direito está intrinsecamente ligado à troca de bens e não pode existir separado dessa troca. Ou seja, entre a lógica que governa as mercadorias como uma forma de troca e a lógica governando a forma do direito existe uma homogeneidade que torna possível descrever o direito em termos econômicos. O que explica esta homogeneidade é o fato de que abstrações jurídicas fundamentais inevitavelmente refletem relações sociais e, ao mesmo tempo, solidificam essas relações em categorias jurídicas. Pashukanis aceitava o direito apenas enquanto direito civil: direito público para ele era uma contradição de termos, pois tal direito não possui qualquer conexão com alguma relação de troca. Relações jurídicas são sempre formadas por contratos orais ou escritos que determinam regras para transações privadas, e não há realidade jurídica para além desses contratos. Mesmo um regulamento emitido pelas autoridades públicas não é nada mais que um sintoma, a partir do qual é possível prever o que o direito será. Para Pashukanis, o direito está na coordenação das vontades conflitantes de vendedores e compradores; ele estava convencido de que o direito burguês era impecável e atendia perfeitamente às exigências do fluxo e da troca de bens. Como o estado socialista não buscava promover relações de troca, não haveria nenhuma necessidade pelo direito, que desapareceria assim que o Estado assumisse controle total das relações econômicas.

O pensador russo-letão Peter Stuchka (Pēteris Stučka, 1865-1932) - um dos ideólogos da Nova Legalidade Socialista, bem como presidente da Suprema Corte da Rússia Soviética (19231932) - estudou direito do ponto de vista da teoria de classes. Ele defendeu que a função do direito é fornecer um arcabouço ideológico para os comandos da classe governante, e se esforçou para justificar a desigualdade entre as classes. Enquanto houver mais de uma classe em uma sociedade, essa sociedade estará fadada a possuir o direito. Isso explica por que até mesmo a Rússia Soviética possuía seu próprio “direito do proletariado”, que refletia o domínio do proletariado sobre as outras classes. Argumentando que é a vontade da classe dominante que determina os conteúdos e a forma do direito positivo, Stuchka buscou desmistificar o direito como nada além da dominação de uma classe sobre outra. A liberdade, a igualdade e outros valores da filosofia jurídica burguesa são apenas fetiches servindo ao controle da classe dominada. Esse entendimento do direito enquanto ferramenta de supressão de classe sustentou a prática dos tribunais revolucionários durante a Guerra 
Civil Russa. Em meados de 1920, Stuchka promoveu uma definição do direito como "um sistema (uma ordem) de relações sociais correspondentes aos interesses da classe governante e protegidas pelo poder organizado desta classe governante”. As ideias de Stuchka influenciaram profundamente o desenvolvimento do sistema jurídico soviético, particularmente a doutrina judicial que estabeleceu o interesse de classe como critério principal para a adjudicação civil e procedimentos penais.

Uma versão psicológica da teoria jurídica marxista foi elaborada por Mikhail Reisner (1868-1928). Professor na Universidade de Petrogrado e seguidor de Petrazycki, ele tentou inserir a teoria psicológica do direito numa fundação marxista. Reisner tornou-se proeminente em 1917 como um dos principais teóricos do direito soviético. Sua principal ideia era que cada classe definiria intuitivamente o que é justo e apropriado em relação à sua posição na sociedade e aos seus objetivos na luta de classes. Essas intuições fizeram surgir um direito de classes específico, que é um produto da consciência jurídica coletiva. Segundo Reisner existem dois aspectos básicos do direito: a vontade das classes, que reflete os direitos subjetivos das classes, e o atrito entre essas classes, que cria um direito objetivo. Ambos os aspectos estão coordenados, no sistema geral do direito, por meio da luta de classes por igualdade na sociedade. A classe dominante impõe sua consciência jurídica e, portanto, o seu direito, às classes subjugadas, por meio da tomada de controle do mecanismo ideológico, que influencia a formação da consciência jurídica geral. Uma vez que a consciência jurídica pode afetar diretamente as relações sociais, em uma "consciência revolucionária” predominante, sem a intermediação do direito positivo, o novo direito do proletariado não precisaria de nenhum regulamento, pois seria capaz de governar por meio de sugestões psicológicas.

No final dos anos 20, a ciência do direito soviética viveu um período de florescimento: diversas abordagens alternativas ao direito, que competiam não apenas em termos teóricos, mas também por influência nas políticas e na prática jurídica, foram desenvolvidas. As discussões teóricas tiveram um impacto evidente na implementação de programas políticos como a coletivização. A base para uma abordagem teórica monista do direito foi lançada durante o Primeiro Congresso de Teóricos do Direito Marxistas em 1931. O objetivo deste congresso era estabelecer uma abordagem unificada para o direito, que ecoaria na política geral do Partido Comunista. Este objetivo não foi imediatamente alcançado, e os debates continuaram até a metade dos anos 30 . Como foi sugerido pela ideologia oficial adotada pelo Partido Comunista da URSS, a base filosófica para cada investigação já havia sido determinada nos clássicos (de Marx, Engels, Lenin e Stalin) e, assim, os cientistas do direito estavam “dispensados” das especulações filosóficas e reflexões: esperava-se que eles apenas aplicassem o dogma marxista-leninista à realidade jurídica.

Revista da Faculdade de Direito - UFPR, Curitiba, vol. 60, n. 3, set./dez. 2015, p. 39-58 
Isto explica por que a filosofia do direito nos anos 30 foi completamente substituída pela teoria do direito, que foi pensada para ter uma função exclusivamente instrumental. Argumentações amplamente filosóficas sobre o direito foram condenadas, por Lenin e outros líderes políticos, como marcas da ciência jurídica burguesa decadente (pensada para enganar a classe trabalhadora e desviar sua atenção da luta de classes) - e foi assim que a filosofia do direito viu seus últimos dias na jurisprudência soviética. A nova ciência jurídica socialista deveria assumir apenas um objetivo como seu objeto: ajudar a desenvolver as leis e decretos que implementariam a vontade da classe trabalhadora. Evidentemente não havia qualquer sentido em um advogado questionar qual exatamente era a vontade da classe trabalhadora ou, ainda, se ela coincidia com a vontade das elites governantes soviéticas.

De todas as ciências sociais na sociedade moderna, a ciência do direito parece ser a mais ideologicamente direcionada (pois possui uma função reguladora da qual as autoridades políticas podem se apropriar). Este lugar que a teoria do direito ocupou na Rússia Imperial explica por que todos os problemas sociais importantes do começo do século XX se tornaram objeto de investigação da filosofia do direito, e foram discutidos como problemas jurídicos da perspectiva da filosofia do direito. Essa filosofia ofereceu ideias e munição para aqueles que estavam em qualquer dos lados do espectro sociopolítico: para aqueles que queria refrear o desenvolvimento social, temendo sua imprevisibilidade (essa era a ala conservadora da intelligentsia), e para aqueles que buscavam trazer mudanças para a sociedade, seja por reformas (essa era a visão da maioria entre os intelectuais) ou mediante a revolução social (bolcheviques e anarquistas). Nos primeiros anos depois da Revolução de Outubro de 1917, a teoria jurídica continuou a exercer um papel importante na vida intelectual do País. Mas o controle ideológico rígido devido à realidade política da URSS gerou eventos catastróficos para essa disciplina, que foi pressionada a servir como uma ferramenta da ideologia comunista no início dos anos 30. Nos sessenta anos de governo soviético que se seguiram, a teoria do direito existiu em isolamento, agindo atrás de uma cortina de ferro ideológica. A disciplina tornou-se uma mistura de preceitos contraditórios e idiomas dispersos baseados nos "clássicos" (Marx, Engels, Lenin), cozinhando em seu próprio suco e temperada com alguns esquemas e concepções derivados da ciência jurídica pré-revolucionária. Esta sopa assumiria uma variedade de sabores, e de fato isso ocorreu com uma uma série de nuances terminológicas que seriam compreendidas como se possuíssem grande alcance nos debates intelectuais daquele tempo (uma espécie de Escolástica). O problema com essa situação foi aparente para os teóricos do direito, mesmo em 1980. A perestroika dos anos 90 reanimou a atividade intelectual entre os teóricos do direito russos, que apressaram-se em construir seus próprios conceitos. Alguns desses teóricos 
concentraram-se no desenvolvimento da filosofia do direito ao redor do mundo e involuntariamente repetiram os lugares-comuns: seus "novos” esquemas, portanto, acabaram sendo sem efeito, falhando em contribuir com qualquer coisa original ou útil no debate mundial. A maioria dos filósofos do direito, porém, escolheram não desviar de seus caminhos, descartando os preceitos da ideologia soviética, mas mantendo todo o resto, trabalhando assim na tradicional jurisprudência dogmática soviética. Esta estratégia ainda é aparente na maioria dos livros sobre teoria do direito, que reproduzem os esquemas teóricos da era soviética e os investem de novos conteúdos ideológicos (direitos humanos, liberdades, democracia e outras coisas do gênero). Nos anos 2000, essa tendência dominava a academia. Por isso é que a ciência jurídica russa é constantemente lembrada como retrógrada, pouco atenta aos debates na ciência do direito internacional. E esta é uma difícil escolha que a jurisprudência russa enfrenta agora: ou reconhece seu caráter retrógrado e tenta acompanhar a teoria do direito mundial, ou continua descartando o desenvolvimento internacional da filosofia do direito. Na minha opinião, essas são as duas maiores tendências da jurisprudência teórica em nosso país, cada uma certamente permitindo variações e nuances significativas.

\section{CAPÍTULO 2}

Com a sua Declaração de Soberania do Estado (1990), a Rússia, de fato, declarou independência da União Soviética (agora celebrada no dia 12 de junho, como Dia da Independência Russa). Este movimento foi seguido por declarações similares de outros territórios. Declarações de soberania não vieram apenas das repúblicas soviéticas, mas, também, de “repúblicas” dentro da Rússia (incluindo Tataristão e Chechênia [1990]). Utilizando as pioneiras técnicas legislativas de Eltsin, estas entidades territoriais começaram uma campanha pela independência: mais da metade destas “repúblicas” proclamaram soberania em suas constituições. O Tratado Federal de 1992 colocou a Rússia em igualdade com suas repúblicas (estados); a soberania das repúblicas foi mencionada e implicitamente reconhecida neste documento constituinte precedendo a adoção da Constituição Russa de 1993. Mas, passo a passo, a Câmara Civil da Federação Russa aniquilou a concepção de soberania compartilhada (pertencente tanto à federação quanto aos seus estados), determinando inválidas as cláusulas de soberania diferentemente formuladas nas constituições “regionais”; esses passos foram acompanhados por reformas de centralização iniciadas por Putin durante seu primeiro mandato na presidência. Isto marcou a primeira onda de debates sobre soberania. 
Uma vez que a integridade do País foi restaurada depois de meados dos anos 2000, os debates tomaram outra direção; desta vez, sobre os limites da independência da Rússia na esfera da lei internacional e das organizações internacionais (a Convenção Europeia de Direitos Humanos [CEDH], a corte das Nações Unidas, a Corte Internacional Criminal). Esses debates foram marcados em anos recentes por uma calorosa polêmica sobre os “limites de concessão” (Zor’kin, presidente da suprema corte), controvérsias entre a CEDH, a Câmara Cível da Federação Russa e o Conselho de Segurança da Federação Russa sobre os "limites da interferência em assuntos internos” (casos de Markin e de Kudeshkina), e críticas afiadas do presidente da Suprema Corte Comercial, Ivanov, contra “competição injusta” de jurisdições estrangeiras, durante o Fórum Judicial de 2012. Mesmo que, de acordo com a sua constituição, a Rússia se mantenha ligada à concepção monista de ordem legal, este problema é agora reiterado com referência ao problema da soberania, e várias autoridades (incluindo os juízes mais importantes) tendem a interpretar o artigo 15 da constituição como implicando no esquema dualista: apenas aquela ordem legal internacional que é reconhecida pela Rússia, como Estado soberano, é válida; a vontade de poderes internacionais e estrangeiros não pode prevalecer sobre a vontade soberana da Rússia. Os debates estão longe de terminar, e os juristas não são unânimes. É interessante especular sobre a estrutura conceitual destes debates e, assim, sobre os possíveis resultados. Estes debates são acontecem em vários campos da prática jurídica e da teoria do direito. Em seguida investigaremos suas repercussões no campo dos direitos humanos.

A Rússia representa um caso particular para o estudo da conexão entre a conceituação de soberania e as ações práticas adotadas por políticos e legisladores no campo dos direitos humanos e das instituições democráticas. Na tradição jurídica ocidental a ênfase em uma democracia liberal enquanto sistema é colocada na proteção da liberdade individual. Os debates políticos russos fazem referência à democracia genuína (antiga, medieval), em que se dá ênfase ao bem-estar da organização política, e não ao dos indivíduos enquanto membros desta organização. A partir desta perspectiva, a democracia também pode ser vista como o instrumento de proteção do interesse nacional, ao invés do interesse individual - esta é a principal tese reiterada por diversos políticos e juízes influentes na Rússia.

O Tratado de Vestefália, de 1648, marcou o início da doutrina contemporânea do Estado soberano enquanto poder irrestrito absoluto. No século XVI, Jean Bodin definiu “soberania” como “absoluto e perpétuo poder”. O soberano é aquele que detém absoluto e perpétuo poder, sem nenhuma limitação. O filósofo alemão Georg Jellinek escreveu, no século XIX, que poder de Estado é poder que não conhece nenhum poder superior; assim, é independente e é o poder supremo. 
Ele fez a distinção entre soberania externa (independência de um Estado) e soberania interna (o direito do soberano de arbitrariamente decidir um assunto pertinente ao desenvolvimento interno). Esta é ainda a doutrina dominante na teoria legal russa, bem como para muitos estudiosos em lei internacional russa; poucas coisas mudaram desde o século XIX. A situação política e a ideologia do antigo regime Soviético e das elites dominantes de hoje fizeram estas mudanças indesejáveis anteriormente, e agora estas mudanças estão maduras o suficiente para serem implementadas.

De acordo com a concepção tradicional de soberania, o soberano é aquele que exerce tal poder; o soberano tem o direito de decidir arbitrariamente sobre qualquer questão interna. Este entendimento ainda é dominante na doutrina russa do direito internacional; poucas coisas haviam mudado desde o século XIX. Atualmente muitos teóricos afirmam o fim do pretenso monopólio da soberania na escala do Estado-nação. Afirma-se que a conexão necessária entre Estado e a “soberania de Vestefália” não é mais relevante no mundo contemporâneo. Direitos humanos, segurança global, troca e comércio, e muitos outros campos sociais importantes são regulados e protegidos em nível global, de forma que Estados nacionais específicos estão vinculados com os padrões internacionais (regras, princípios) nesses campos e não podem fazer o que quiserem com os direitos humanos, mesmo utilizando-se do argumento da soberania.

Esta perspectiva tornou-se uma das mais controversas para os políticos e proeminentes advogados russos. Poderia o Estado abdicar de sua soberania pelo bem da proteção dos direitos humanos? Desde 2008 se tornou popular, entre os oficiais, referir-se, ao bloco de ideias, sob a alcunha de democracia soberana. Assim, Vladimir Putin insiste que a

Rússia deve decidir, ela mesma, sobre como melhor se poderiam implementar os princípios de liberdade e democracia, levando em consideração sua história, geopolítica e outras especificidades. Como um Estado soberano, a Rússia pode - e vai - estabelecer para si mesma, independentemente, os prazos e as condições para atravessar este caminho.

Isso significa fazer uma conexão necessária entre a preservação da soberania estatal e a preservação do controle do Estado; isto inclui o controle sobre grandes indústrias e uma forte ideologia estatal. Neste aspecto, soberania significa que o Estado não está mais vinculado a nenhum padrão e política internacional em seu desenvolvimento; esses padrões e políticas tem meramente força persuasiva e se tornam vinculadores apenas após autorização (ratificação ou outra forma) pela Rússia como Estado soberano. Questionando se há alguma especificidade na posição formulada pela jurisprudência dominante russa, alguém poderia perguntar se essas ideias baseiam-se em outras ideias básicas da filosofia do direito russa e se apelam para representações específicas dos russos sobre as leis e o Estado.

Revista da Faculdade de Direito - UFPR, Curitiba, vol. 60, n. 3, set./dez. 2015, p. 39-58 
Argumentando que haveria alguma especificidade na cultura russa do pensamento jurídico, nós não compartilhamos das conclusões conservadoras duvidosas, de que os russos possuem uma mentalidade incapaz de compreender o valor social do Direito. A primeira proposta (de uma mentalidade particular) não envolve necessariamente a segunda (do niilismo jurídico). A despeito das complicações do desenvolvimento histórico (o jugo tártaro, a autocracia czarista, ou o domínio comunista), a Rússia, no seu todo, pertence à tradição jurídica continental da civilização ocidental. A diferença ainda assim é perceptível e, como argumenta Bill Bowring, "há uma distintiva tradição russa de pensamento e argumentação sobre os direitos humanos”. Essa tradição não se encontra no nível do místico Volksgeist, mas na maneira como se ensina o direito aos estudantes e como juízes e autoridades que aplicam o direito são instruídos para encontrar, proteger e aplicar a lei.

Historicamente essa visão de mundo expressou-se nas ideias filosóficas sobre uma unidade mística-religiosa entre a sociedade e a individualidade, naquilo que Berdyaev caracterizou como "o conflito eterno entre o instinto de poder do Estado e o instinto de liberdade e sinceridade do povo". De acordo com Berdyaev, um dos resultados dessas ideias pode ser visto no infeliz experimento em que a Rússia comunista fingia realizar os tradicionais valores russos de sobornost ou comunitarismo (a ideia mística de integração religiosa de um indivíduo à espiritualidade coletiva). A visão desses padrões culturais pode explicar melhor algumas ideologias oficiais contemporâneas e sua aceitação, do que alusões ao jogo entre políticos engenhosos e o povo inocente, cinicamente manipulado pela mídia de massa, ou do que a reiteração da ideia de reaparecimento da ideologia soviética.

A ênfase na coletividade que se sobrepõe à individualidade foi diversas vezes mencionada como um dos elementos-chave da cultura russa. Essa peculiaridade cultural é vista como promotora de valores de igualdade e fraternidade comunitária, deslocando a ênfase do comunitário solitário para a experiência congregacional da comunidade. Esse desvio para a filosofia ideal-realista russa não resulta na aniquilação da individualidade pelo bem da universalidade, mas idealmente busca um desenvolvimento mais completo da personalidade que só pode existir como parte de uma totalidade (o povo, a Igreja, a comunidade rural. O espaço entre essa dimensão ideal e a realidade histórica da dominação do coletivo sobre o individual é explicado, para Bardyayev, Vladmir Soloviev e muitos outros intelectuais russos, pela religiosidade ortodoxa, segundo a qual a existência individual é justificada exclusivamente na perspectiva escatológica da salvação que, por sua vez, é possível apenas por meio da ação coletiva. Esta hipótese filosófica da união entre o social e o individual poderia facilmente divergir dos pensadores russos do modelo “Ocidental” de democracia, cuja função principal é controlar a ação do governo contra seu povo. A ideia de uma união espiritual entre o povo e o governo é reforçada pelo "modelo antigo" de democracia, em que o Estado 
(aparelho político) e o povo devem trabalhar em uma "sinfonia” (a antiga ideia bizantina que penetrou na Rússia no início da Idade Média) para salvaguardar a totalidade da desintegração. A relação orgânica entre o povo e o governo pressupõe que eles são espiritualmente unidos para realizar uma "ideia nacional” (mais um slogan poderoso no vocabulário dos conservadores russos), a qual apareceu recentemente na forma de “democracia soberana”.

O principal idealizador desta ideia é Vladislav Surkov, que em 2006 era o Chefe de Administração do presidente russo. A retórica em torno da democracia soberana foi desenvolvida por Surkov com base no conjunto de ideias introduzidas pelo famoso neoconservador Francis Fukuyama. A contribuição mais impressionante para os debates foi feita durante a Mesa Redonda $O$ Estado soberano nas condições da globalização: democracia e identidade nacional (30 de agosto de 2006), na qual, referindo-se às ideias eslavófilas (“o povo russo deve desenvolver-se organicamente, deve ter uma representação total de si mesmo”), Surkov clamou por uma democracia soberana que "apela para a dignidade do povo russo e da nação russa em geral”. A posição dos autores deste conceito foi escrita em uma coleção de artigos nos quais Surkov e outros autores insistiram que a Rússia tem uma vocação especial para proteger suas especificidades nacionais contra o niilismo ocidental.

No discurso de 2007, Soberania enquanto equivalente político da competição, Surkov propôs a "democracia soberana” como uma estrutura social em que o poder supremo (suprema potestas de Jean Bodin) pertence à nação russa, que é inteiramente independente das forças externas (isto é, do Ocidente). Existem três premissas conceituais básicas de democracia soberana: (1) a soberania prevalece juridicamente sobre a democracia (liberal); (2) pode-se corretamente balancear os direitos soberanos do Estado com os direitos humanos individuais, pois existe uma "relação orgânica” entre o povo e o governo, e porque o individual não é nada mais do que uma parte do coletivo; (3) a tradição democrática não deverá ser introduzida, na Rússia, vinda de fora, mas deverá ser encontrada na cultura estatal milenar russa que se baseia nas tradições comunitárias. Interesses individuais não podem sobrepor-se aos interesses sociais, e, no caso de um conflito, os direitos de certos indivíduos podem ser sacrificados em nome de direitos nacionais e coletivos (i.e., os direitos do povo/nação de ser soberano - politicamente, economicamente, culturalmente e em muitos outros aspectos). A principal conclusão política desta doutrina é a conexão entre a manutenção da soberania estatal e a preservação do controle estatal, incluindo a introdução de uma forte ideologia de Estado para isolar, da crítica internacional, o poder político. A principal tarefa desta ideologia conservadora é garantir a integridade do País, o que requer evitar prontamente qualquer ameaça vinda do Ocidente e de seus membros dentro da Rússia. A Rússia deve mover-se 
em direção à democracia com cautela, sob o controle permanente do governo. É questionável se esse conceito político enfraquece a ideia universal de democracia, e se existem universalidades no mundo multicultural pós-moderno, mas ambas as questões nos redirecionariam para um debate filosófico vasto que está além dos limites deste trabalho. No contexto do presente artigo é suficiente indicar as principais implicações filosóficas desta posição: o interesse coletivo precede o interesse individual.

A democracia soberana foi discutida por vários meses e, aproximadamente um ano de discussões depois, caiu em desuso. O (então) presidente Medvedev alegou que "pegar a palavra “democracia” e começar a anexar qualificadores a ela pareceria um pouco estranho”, e Zor'kin sugeriu que essa ideia foi uma forma confusa de constitucionalismo. Ao mesmo tempo, Vladimir Putin não se posicionou expressamente sobre o conceito de Surkov, mas, indiretamente, defendeu as bases ideológicas e filosóficas sobre as quais seu assistente construiu a ideia de democracia soberana. Essas bases foram formadas em 2005 quando, em seu discurso ao parlamento russo, Putin enfatizou que a Rússia deveria encontrar seu próprio caminho para construir uma "sociedade democrática, livre e justa”. E, em fevereiro de 2012, Putin referiu-se novamente a essa ideia "para reanimar o estado, [e] restaurar a soberania popular que é a base de uma verdadeira democracia”.

A relutância em conceder prioridade aos direitos humanos sobre todas as outras preocupações (segurança nacional, integridade do país...) é explicável não apenas do ponto de vista político, mas também do teórico. Nos debates contemporâneos a soberania é mais aceita como soberania externa, isto é, a integridade e independência do Estado em relação a outros Estados e à comunidade internacional (que de fato traduz a vontade de superpotências, de acordo com a ideologia oficial). Ao mesmo tempo, existe uma falta de distinção entre soberania do povo, da nação e do Estado; soberania é usada em todos os seus sentidos para o mesmo propósito ideológico. Os “debates sobre soberania” também não são sempre separados da questão sobre ordem legal monista/dualista; assim, aceitar a prioridade da lei internacional pode ser facilmente (mas erroneamente) considerada como uma ameaça à soberania. Falta distinção, também, entre a concepção de soberania e de força vinculadora dos direitos humanos (eles dependem de adesão do Estado, em padrões internacionais legais, ou de leis naturais de razoabilidade e sociabilidade?) Uma abordagem mais crítica do problema da soberania é necessária, a qual levaria em consideração essas questões.

A limitação da soberania dos Estados-nação dentro da estrutura de associações interestatais - por exemplo, a União Europeia; os extensivos poderes de organizações supranacionais; a globalização econômica com a emergência de grupos transnacionais autorregulados; o direito de um 
ataque preventivo contra um Estado soberano que seriamente ameaça a estabilidade internacional; se o Estado comete violação de direitos humanos em massa ou por outras razões críticas (Carta das Nações Unidas). Estas realidades recaem fora do esquema tradicional como descrito acima, sua explicação requer uma revisão deste esquema; tanto políticos quanto juristas estão relutantes, na Rússia, em fazer esta revisão, achando mais fácil manter-se na linha dos antigos esquemas conceituais, datados da época da ciência jurídica soviética (e ainda da pré-revolucionária filosofia do direito da Rússia Imperial, no início do século XX).

Reiterando essa ideia de uma "Democracia à la russe” dos líderes políticos e juízes seniores (com ou sem referência à democracia soberana), transmitem-se aos russos três mensagens ideológicas principais sobre a correlação entre direitos individuais e coletivos.

A primeira diz que as fontes de legitimidade e soberania são encontradas no poder estatal, e não na sociedade ou na comunidade internacional. Essa mensagem traduz-se por um simples silogismo: considerando que o povo russo é o único detentor da soberania (art. $3^{\circ}$ da Constituição da Rússia), e considerando que o povo não exerce sua vontade diretamente (exceto durante eleições e referendos) e delega este exercício ao governo, segue a ideia de que o governo tem o direito de em nome do povo - realizar quaisquer medidas para proteger a soberania popular e nacional (estas duas formas são pouco diferentes na ciência política russa) indispensável para a sobrevivência do povo. Assim, nenhuma corte ou agência internacional pode interferir com as atividades do governo ou mesmo criticar com base no humanitarismo ou outros padrões.

O medo da imprevisibilidade social e política e o comunitarismo tradicional criam uma atmosfera favorável para o isolacionismo, defendido pelos representantes do Estado como "um caminho separado de desenvolvimento” da Rússia. Assim, a proteção da soberania a qualquer custo pode ser facilmente justificada como conditio sine qua non para a sobrevivência do povo russo. Na opinião de alguns autores, tal experiência histórica contribuiu para a formação do "espírito de desventuras na esfera pública” na cultura russa, que resulta em uma abstenção passiva e na desconfiança em relação a qualquer tipo de discurso político, incluindo aquele sobre democracia e direitos humanos. Dada essa inércia tradicional dos russos quanto aos problemas políticos, o governo pode agir independentemente da opinião pública, desde que os russos não “amadureçam” o suficiente para serem amplamente engajados na deliberação política. Mesmo que tais conclusões sejam altamente questionáveis, elas podem ao menos explicar parcialmente os objetivos da “estratégia de mobilização” empregada pelas autoridades para clamar vigilância aos intelectuais em relação aos valores ocidentais. Se existe alguma desconfiança nas grandes narrativas sobre os 
direitos humanos entre alguns dos russos, a retórica sobre soberania pode aumentar essa desconfiança e reforçar a legitimidade das autoridades outrora desafiadas pela crítica ocidental.

Em terceiro lugar, o Ocidente caminha na direção errada (a antiga ideia do "Ocidente decadente” proposta pelos eslavófilos e apreciada pelo regime soviético) e a Rússia não deveria seguir este caminho, abandonando sua soberania. Abandonar a soberania em favor de uma regulação internacional mais fraca levaria ao domínio de corporações transnacionais e oligarquias. A Rússia não seguirá esse novo paradigma, pois ele não se conforma com a Constituição e com as leis da Rússia (que são evidentemente baseadas no conceito vestefaliano de soberania), e é destrutivo para a sociedade. Essa velha ideia do “Ocidente decadente” oferecida pelos eslavófilos e apreciada pelo regime soviético (“capitalismo decadente”) assume seu papel também em afastar os argumentos globalizadores ("pode ser verdade para o ocidente decaído, mas não para a Rússia que se mantém fiel as tradições estadistas”). Os perigos da globalização poderiam tornar-se verdadeiros se a Rússia se engajasse na cultura cosmopolita e acabasse admitindo a universalidade da democracia ou dos valores humanitários, destruindo assim a sua idiossincrasia nacional. Estes argumentos, reiterados por Putin e outros políticos conservadores contemporâneos, já haviam se expandido amplamente durante o século XIX. Assim, tal engajamento pode ser perigoso, e a Rússia deveria manter uma distância segura da ideologia jurídica promovida pelas cortes e organizações internacionais.

A Rússia está agora num momento perigoso de sua história; este país é concebido pelos seus líderes como uma grande potência, com uma história gloriosa e um futuro promissor. Mas, mesmo em posse de grandes potenciais (recursos naturais, capital humano), a Rússia não está em igualdade com as democracias ocidentais em termos de valor. Isto provoca o sentimento de tratamento injusto recebido de outros, o que se torna fonte das preocupações descritas sobre democracia e soberania. Ao mesmo tempo, ansiedade sobre a desintegração do País ainda existe: a chamada "parada de soberanias” do início de 1990 não está esquecida, assim como a instabilidade daquele tempo. Estes dois fatores principais (juntamente com a propaganda oficial de melhores condições de vida sob o novo regime, medo da imprevisibilidade política e social, e o tradicional comunitarismo e estatismo do pensamento jurídico russo) criam uma atmosfera favorável a movimentos de isolamento atribuídos pelos oficiais como "um caminho separado de desenvolvimento” da Rússia soberana. 


\section{REFERÊNCIAS}

Antonov Mikhail, Beyond formalism: sociological argumentation in the "Pussy Riot" case, in: Revista Critica de Derecho Canonico Pluriconfesional. 2014. No. 1. P. 15-25;

, Conservatism in Russia and Sovereignty in Human Rights, in: Review of Central and East European Law. 2014. Vol. 39. P. 1-40;

Du droit byzantin aux pandectistes allemands: convergences de l'Europe occidentale et de la Russie, in: Identita del Mediterraneo: elementi russi. )Cagliari: AM\&D Edizioni, 2012). P. 253263;

, Foreign Court Decisions, Arbitral Awards and Sovereignty in Russia, in: Review of Central and East European Law. 2013. No. 38. P. 317-340;

, Russian Legal Philosophy in the 20th Century, in: E. Pattaro, C. Roversi (eds.) A Treatise of Legal Philosophy and General Jurisprudence, Volume 12(1), Legal Philosophy in the Twentieth Century: The Civil Law World (Berlin: Springer Verlag, 2015), in print;

, Theoretical Issues of Sovereignty in Russia, in: Review of Central and East European Law. 2012. No. 37. P. 95-113;

, Unser schwerer Weg zum Recht: Grundprobleme der modernen theoretischen Rechtswissenschaft in Russland, in: Rechtstheorie. 2007. No. 38(1). P. 1-12;

Averre Derek, Sovereign Democracy and Russia's Relations with the European Union, in: Demokratizatsiya. 2007. No. 15(2). P. 173-190;

Berdyaev Nicolai, The Origin of Russian Communism (G. Bles, London, 1937);

Berlin Isaiah, Russian Thinkers (Penguin Books Ltd, London, 1978);

Bowring Bill, Rejected Organs? The Efficacy of Legal Transplantation, and the Ends of Human Rights in the Russian Federation, in: Esin Orucu (ed.), Judicial Comparativism in Human Rights Cases (UKNCCL, BIICL, London, 2003). P. 159-182;

Duncan Peter, Russian Messianism: Third Rome, Revolution, Communism and After (Routledge, London, 2000);

Fukuyama Francis, The Great Disruption: Human Nature and the Reconstitution of Social Order (Free Press, New York, NY, 1999);

Haller Gret, Human Rights Without Democracy? Reconciling Freedom With Equality (Berghahn Books, Oxford, 2012);

Jakim Boris and Bird Robert (eds.), On Spiritual Unity: A Slavophile Reader (Lindisfarne Books, Hudson, New York, NY, 1998); 
Kahn Jeffrey, Russia’s 'Dictatorship of Law' and the European Court of Human Rights?, in: Review of Central and East European Law. 2004. No. 1. P. 1-14;

Kelsen Hans, Principles of International Law (Holt, Rinehart and Winston, New York, NY, 1967);

Krastev Ivan, Russia as the 'Other Europe’, in: Russia in Global Affairs. 2007. No. 4. P. 66-78;

Kryshtanovskaya Ol'ga and White Stephen, The Sovietization of Russian Politics, in: Post-Soviet Affairs. 2009. No 25(4) P. 283-309;

Mälksoo Lauri, The History of International Legal Theory in Russia: A Civilizational Dialogue with Europe, in: European Journal of International Law. 2008. No. 19(1). P. 211-232;

Popper Karl, The Open Society and Its Enemies, in 2 vol. (Princeton University Press, Princeton, NJ, 1971);

Reisman Michael, Sovereignty and Human Rights in Contemporary International Law, in: The American Journal of International Law. 1990. No. 84(4). P. 866-876;

Riasanovsky Nicolai, Russia and the West in the Teaching of the Slavophiles: A Study of Romantic Ideology (Harvard University Press, Cambridge, MA, 1952);

, Russian Identities: A Historical Survey (Oxford University Press, Oxford, 2005);

Roberts Anthea, Comparative International Law? The Role of National Courts in Creating and Enforcing International Law, in: International and Comparative Law Quarterly. 2011. 60(1). P. 5792;

Ryzhkov Vladimir, Sovereignty vs. Democracy?, in: Russia in Global Affairs. 2005. No. 4. P. 101112;

Sakwa Richard, Communism in Russia: An Interpretative Essay (Palgrave Macmillan, Basingstoke, 2010);

Suverennaja demokratija: ot idei k doctrine [Sovereign democracy: from idea to doctrine] (Evropa, Moscow, 2006) [In Russian];

Truscott Peter, Russia First: Breaking with the West (I. B. Tauris, London, 1997);

Walicki Andrzej, The Slavophile Controversy: History of a Conservative Utopia in NineteenthCentury Russia (Clarendon Press, Oxford, 1975);

Weiler Jonathan, Human Rights in Russia: A Darker Side of Reform (Lynne Rienner Publishers, Boulder, 2004);

Zenkovsky Vasily, A History of Russian Philosophy (Routledge \& Kegan Paul Ltd., New York, NY, 1953). 


\title{
SOVEREIGNTY IN THE LIGHT OF RUSSIAN LEGAL PHILOSOPHY
}

\begin{abstract}
In the present paper we will analyze one of the trends of Russian legal philosophy which exerts a considerable influence on the political processes on-going in this country. This trend is revealed in so called state-centralism: an ideology according to which the State is omnipotent and can interfere with any matters without any limitation from inside or outside. This "ideology of Leviathan” has been many times articulated in legal philosophy, to begin with Plato or Aristotle. In Russia this ideology has found a fertile soil, as its waste spaces, heterogeneous population and unfriendly environment (both in political and natural senses) made it clear for many that without powerful central authorities there will be no further for such a big country. To wit, it will either fall apart as the French, British and other empires, or will need to get modernized and restructured according to the models of other big Western counties (like the US). This paper is developed on the base of two lectures that the present author gave in 2013 and 2014 at Law School of the Federal University of Parana grace to kind invitation and support of this School and to relentless efforts of Professor Cesar Serbena. We do hope that this paper will be an important adjunct to our lectures and will be helpful to those of our Brazilian colleagues who seek to understand the actual political situation in Russia, its implications and perspectives in the light of philosophical debates that underpin these discourses.
\end{abstract}

KEYWORDS: Russia. Sovereignty. Legal Philosophy. 